\title{
OPEN GOVERNMENT PARTNERSHIP: LABORATÓRIO TEÓRICO COM A ANTROPOLOGIA DA TECNOLOGIA
}

\author{
E A TEORIA ATOR-REDE
}

\author{
OPEN GOVERNMENT PARTNERSHIP: THEORETICAL \\ LABORATORY WITH TECHNOLOGY ANTHROPOLOGY AND THE \\ ACTOR-NETWORK THEORY
}

\author{
Matheus Henrique Souza Santos ${ }^{1}$ \\ Milena Pavan Serafim²
}

\section{RESUMO}

O objetivo deste trabalho é analisar, no campo teórico, a elaboração do conceito de ator nos estudos de Science, Technology and Society (STS) para entendimento da Open Government Partnership (OGP), ou Parceria para Governo Aberto. A OGP é uma iniciativa política global fundada por sete países e que, atualmente, já conta com a participação de mais de 100 nações, sendo seu objetivo ressignificar as administrações públicas pelo fortalecimento da participação social e do combate à corrupção, com atuação mais eficiente e efetiva dos serviços e políticas públicas, ao passo que implementa novas tecnologias de informação e comunicação. Para tanto, esta reflexão teórica busca: (i) reconhecer e estudar a OGP como ator e a (ii) importância da rede de atores para sua implementação nos países participantes. Para tanto, opta-se pela abordagem dos estudos de STS no âmbito da antropologia da tecnologia e, em seguida, compreendendo o método científico Ator-Rede ou Semiótica Material. Nessa área de conhecimento, com seus conceitos e abordagens, é possível optarmos por uma análise descritiva da Open Government Partnership, entendendo que a própria OGP é ator principal que incide sobre a(s) rede(s) de outros atores, ao passo que esses também têm certa liberdade para se adequar segundo as necessidades, peculiaridades, objetivos e conjunturas (narrativas) a que estão submetidos.

Palavras-chave: Open Government Partnership. Antropologia da Tecnologia. Ator-Rede.

\section{ABSTRACT}

The aim of this paper is to analyze, theoretically, the elaboration of the concept of actor within the studies of Science, Technology and Society (STS) for understanding of the Open Government Partnership (OGP). The OGP is a global political initiative founded by seven countries that currently

\footnotetext{
${ }^{1}$ Doutorando em Política Científica e Tecnológica - Unicamp, Integrante do Grupo de Análise de Políticas de Inovação (GAPI). UNICAMP/ Bolsista CAPES. e - mail: mhsouzasantos@ gmail.com

${ }^{2}$ Atualmente é Coordenadora Geral de Graduação da Faculdade de Ciências Aplicadas - Unicamp. Doutora em Administração Pública pela Faculdade de Ciências Aplicadas Unicamp. e-mail: milenaserafin@gmail.com
} 
encompasses more than 100 nations. Its goal is to redefine public administrations by strengthening social participation, combating corruption. with more efficient and effective performance of public services and policies, while implementing new information and communication technologies. Therefore, this theoretical reflection seeks to: (i) recognize and study the OGP as an actor and (ii) the importance of the network of actors for its implementation in the participating countries. To do so, we choose to approach the studies of STS within the scope of technology anthropology and then comprising the actornetwork or material semiotics scientific method. In this area of knowledge, with its concepts and approaches, it is possible to opt for a descriptive analysis of the implementation of Open Government Partnership understanding OGP itself as the main actor that has effects over other actors, while these also have some freedom to adjust according to their needs, peculiarities, objectives and conjunctures

Keywords: Open Government Partnership. Anthropology of Technology. Network actor.

\section{INTRODUÇÃO}

A Open Government Partnership (OGP) é uma iniciativa global, sem estrutura institucional rígida, depende das organizações públicas, privadas e estatais que a integram e que, atualmente, conta com mais de 100 países (BRASIL, 2014). Seu objetivo é estabelecer entendimento global visando ressignificar o ideário, mas também a prática, da administração pública como um todo, por meio dos princípios: a) aumentar a disponibilidade de informações sobre as atividades governamentais; b) apoiar a participação cívica; c) implementar os mais altos padrões de integridade profissional por todas as nossas administrações, e d) ampliar o acesso a novas tecnologias para fins de abertura e prestação de contas (OGP, 2015). Compreender essa iniciativa com a lupa dos Estudos de Ciência e Tecnologia (STS, na sigla em inglês) requer uma análise e averiguação dos conceitos estabelecidos no campo das Ciências Sociais, entendendo as áreas aplicadas. Dentre os principais conceitos que esta análise se esforça para compreender está o de "ator social", procurando responder a duas reflexões: (i) reconhecer e estudar a Open Government Partnership como ator e a (ii) importância da rede de atores para sua implementação nos países participantes.

O conceito de ator nas Ciência Sociais é algo historicamente debatido e, de acordo com as áreas - Política, Sociologia e Antropologia -, assumirá características peculiares, dessa forma, estabelecendo algumas, porém essenciais, distinções. Aqui se decidiu abordar diretamente as elaborações da antropologia da tecnologia. 
O presente manuscrito está divido em três seções e a conclusão. A primeira, "O que é a Open Government Partnership?", busca apresentar a iniciativa dando destaque às suas características que mais demarcam diálogo com o arcabouço teórico interpelado. Em seguida, "A OGP como ator a ser reconhecido e estudado" fará os debates iniciais, dentro das formulações gerais da antropologia da tecnologia, para apresentar respostas às duas reflexões que norteiam o presente trabalho - os pontos (i) e (ii). A terceira seção, "A teoria Ator-Rede para a OGP”, é o entendimento desse método de investigação científica, oriundo da antropologia da tecnologia, como instrumento analítico da Open Government Partnership. Por fim, são estabelecidos alguns entendimentos finais e o horizonte que a pesquisa deverá seguir, segundo os resultados apresentados.

\section{O QUE É A OPEN GOVERNMENT PARTNERSHIP?}

A pesquisa científica, em seus vários campos possíveis, muito se esforçou para a compreensão da relação entre Estado e sociedade, na análise das instituições e mecanismos que possibilitam um fluxo comunicativo entre o ambiente estatal, o público e o privado de forma democrática. Essa interação se torna mais contundente quando nações pelo mundo começam construir suas Repúblicas do ponto de vista democrático, ou seja, quando a democracia se destaca como modelo de regime político a ser adotado e aperfeiçoado (SANTOS, 2002). Esse novo momento faz crescer a aspiração por participação e controle social por parte dos cidadãos, mesmo encontrando resistências na própria estrutura burocrática estatal e nas forças políticas que compõem as direções da máquina do Estado. Dessa forma, se tornam centrais, no Estado democrático, ambientes e instrumentos que efetivem a participação nos debates públicos, bem como o controle dos atos e ações do poder público por parte da sociedade civil, de maneira indiscriminada. Para tanto, nas últimas décadas foram desenvolvidas diversas instituições participativas, as IP's, que pudessem conduzir a participação e o controle social para dentro do Estado; no entanto, tendo em vista o limite de efetividade que essas instituições podem ter alcançado, discussões sobre possíveis reformulações e elaborações de novas propostas vêm obtendo importância significativa. E, dentre as alternativas que mais crescem, no Brasil e no 
mundo, para inovar a relação entre Estado e sociedade, figura a Parceria para Governo Aberto ou Open Government Partnership (OGP).

A Parceria para Governo Aberto é uma iniciativa internacional construída, primordialmente, por oito governos nacionais junto a organizações civis desses mesmos países, que objetiva garantir compromissos dos participantes no sentido de promover o combate à corrupção; fortalecer a transparência dos atos públicos; investir na utilização de novas tecnologias da informação e comunicação que tornem os governos, dessa forma, eficazes e responsáveis, além de aumentar e qualificar a participação cívica (OGP, 2011). A OGP deve ser compreendida como uma inovação, no campo político/institucional, de um modelo de organização da gestão pública (SANTOS, SERAFIM, 2018) que seja capaz de dialogar diretamente com seus cidadãos, de forma a atender suas aspirações sobre o Estado e os serviços públicos. Ela torna mais efetivos e eficazes os debates e decisões do poder público (CALDERÓN; LORENZO, 2010).

Cada país, a partir do compromisso público assumido, reúne organizações sociais, de classe, do terceiro setor, as universidades e órgãos dos governos. Eles constituem o grupo de trabalho que irá elaborar o Plano de Ação, documento que norteia em todas as frentes os trabalhos da OGP no país ou localidade e que será monitorado e avaliado pelo Mecanismo Independente de Avaliação (Independent Report Mechanism - IRM) (OGP, 2011). O Brasil, por exemplo, já está no 4º Plano de Ação (2018-2021), os demais foram 2011-2013, 2013-2016 e 2016-2018, passando por três governos nacionais distintos (presidentes Dilma Rousseff, Partido dos Trabalhadores, PT; Michel Temer, Movimento Democrático Brasileiro, MDB e Jair Bolsonaro, eleito pelo Partido Social Liberal, o PSL e, atualmente, sem partido) e mantendo o cronograma de trabalho com mudanças significativas (BRASIL, 2020).

Segundo as atas disponíveis dos primeiros planos brasileiros, é possível constatar a participação de movimentos sociais, laboratórios de inovação, ministérios do governo Federal, sindicatos, organizações de classe e instituições sociais de características distintas (BRASIL, 2015). No entanto, desde 09 de dezembro de 2019, por meio do Decreto Presidencial ${ }^{\circ} 10.160$, foi instituída a Política Nacional de Governo Aberto e formado o Comitê Interministerial de 
Governo Aberto, que garante, no inciso II do artigo $2^{\circ}$, o "fomento à participação social nos processos decisórios", mas apresenta, no artigo $5^{\circ}$ e último, a composição com 13 membros, todos do Governo Federal (BRASIL, 2019).

Os atores, ou stakeholders, como são chamados nos documentos da OGP, variam em cada país, não só por causa da força política e de influência de cada participante ou pela composição política dos governos responsáveis, mas também das características institucionais. Como podemos observar no México, outro país co-fundador, é destacável a maior participação de setores e órgãos governamentais, com a composição de instituições sociais estritamente ligadas ao combate à corrupção (MÉXICO, 2019).

A possibilidade de promover mudanças na composição da OGP nos países ou localidades, sem afastamento às determinações originais, é que precipita uma avaliação da Parceria não como instrumento ou política pública e sim como ator. Mas, ator que não é rígido, pré-moldado e delimitado institucionalmente; ator que influencia e é influenciado pelos contextos em que está inserido.

Por isso, este artigo se apresenta como laboratório teórico, correndo os riscos necessários. É esforço científico de identificar as características gerais e singulares da OGP para compreender melhor essa iniciativa; iniciado por dúvidas e propondo não só conclusões, mas outros horizontes antes não pensados. É um trabalho reflexivo de propor o debate da Open Government Partenership como ator a partir da Antropologia da Tecnologia e da Teoria AtorRede.

\section{A OGP COMO ATOR A SER RECONHECIDO E ESTUDADO}

Nossa segunda seção parte de breve reflexão que busca estabelecer o debate no campo da Science, Technology and Society (STS) para adentrar nas reflexões sobre o conceito de ator. Para tanto, é preciso entender as relações de poder no fazer ciência e tecnologia ou, como afirma JOHN LAW (2015b, p. 17) em "STS as method": "Things never have to be the way they are". Ou seja, para o autor é papel da STS, como método científico embutido nos objetos e processos 


\section{Revista \\ Debates Insubmissos}

estudados e na prática científica, decodificar ${ }^{3}$ as realidades postas, considerando as diferenças dos objetos e seus cenários analisados, ao mesmo tempo em que elabora encaminhamentos de convivência múltiplas dessas diferenças (LAW, 2015b). Dessa forma, a questão da formulação de variados métodos e raízes teóricas que sustentam a STS passa por compreender, seja estrutural ou relacionalmente, os enredos compostos pelo poder dentro do ambiente científico e acadêmico, influindo não só na forma como se faz ciência, mas também nas análises e produtos entregues ao fim das pesquisas e em todo o arquétipo cognitivo dos próprios cientistas.

LAW (2015b) afirma que a tecnociência - a indissociação de ciência e tecnologia - é por si só um posicionamento analítico, contrário às ideias que propõem a compreensão separada dos termos. É tanto moldada pela sociedade como molda a própria realidade, ao passo que em um mundo tão assimétrico de poder o conhecimento científico é, irremediavelmente, ideológico. Assim, a tecnociência auxilia na reprodução desse mundo de desigualdades, sendo impossível separar os métodos do seu contexto social. Eles são, em si, rotinas ou procedimentos culturalmente práticos; materialmente baseados; teoricamente implicados; institucionalmente localizados e socialmente moldados (LAW, 2015b).

SHARON TRAWEEK (1993) defenderá que os pesquisadores que se dedicam a compreender as questões sociais e culturais das ciências e tecnologias devem analisar como o poder é (re) produzido nos múltiplos locais e nas formas de fazer ciência e tecnologia, tanto local como globalmente. A autora, pensando as práticas científicas, médicas e tecnológicas como parte da cultura humana, afirmará, assim como LAW (2015b), a importância da diferença no entendimento dos fenômenos ligados à STS. Nos casos em que a tentativa de transferência de conhecimento tecnológico e científico das metrópoles para as colônias africanas fracassou, não houve, por parte dos países imperialistas, a compreensão de que o contexto social de mudanças socioeconômicas é intrínseco ao desenvolvimento tecnocientífico. Um dos efeitos práticos decorrentes é a falsa ideia de que apenas os países desenvolvidos da Europa teriam produzido ferramentas para compreensão dos fenômenos do mundo. Buscando contestar

\footnotetext{
${ }^{3}$ Ou seja, além de decodificar, coloca-se a questão de mostrar que a tecnociência pode ser pensada de formas alternativas.
} 
gonstist:

contundentemente essa premissa, inovações analíticas foram sendo introduzidas nos estudos da STS como a adaptação, por parte de sociólogos, das técnicas dos etnometodólogos, que buscavam compreender apenas a atividade de trabalho e que, agora, devem "caracterizar precisamente como cientistas e engenheiros produzem verbalmente e visualmente seus projetos experimentais, ideias, argumentos e artigos face a face de forma interativa" (TRAWEEK, 1993, p. 08 , tradução própria).

Importante destacar que a Open Government Partnership, quando analisada, deve levar em consideração o quesito da propensão às distorções frente aos seus princípios. Uma vez que a OGP nasce da ação de determinadas nações, mesmo não sendo todas do centro econômico global - o que possibilita certa pluralidade - é possível que repita o erro descrito por Traweek (1993). Ao mesmo tempo, é preciso entender a possível liberdade dos atores elegidos para implementar a OGP em seus países em conseguir, não mera reprodução, mas uma verdadeira ressignificação, respeitando as peculiaridades, necessidades, conjuntura e objetivos de cada nação.

Mas, o desafio aqui posto é compreender a Open Government Partnership como "ator" e não mero conjunto de princípios que regula e orienta outros "atores", no caso, políticas públicas de acesso à dados e informações, de aumento da participação social nas discussões e decisões públicas, de combate à corrupção e de busca de melhor eficácia e efetividade para ações públicas/estatais. No entanto, a OGP não é algo tangível, não tem qualquer órgão global, não tem CNPJ, por exemplo, mas é uma iniciativa dos Estados nacionais e de suas organizações como movimentos sociais, sindicatos, partidos políticos e universidades. Característica essa que dificulta a elaboração de uma ideia de ator dentro da ação institucional e, até mesmo, política.

Outra característica da Open Government Partnership que necessita ser identificada aqui, e que será mais bem explorada ao fim dessa seção, é que a sua formulação está umbilicalmente ligada ao perfil dos atores elegidos e seus movimentos para compor os espaços de decisões, elaborados pelo Estado, com o fim de implementar as políticas públicas de acordo com seus princípios. O que chamo de stakeholders é, para o debate presente, a ideia de ator ou ator social, conforme a referência utilizada, sendo perceptível, nos documentos até aqui 
estudados e elaborados, a importância de escolha e do comportamento destes para a OGP (BRASIL, 2014; OGP, 2011; OGP, 2015; SANTOS, SERAFIM, 2018).

Partindo do esforço de (i) reconhecer e estudar a Open Government Partnership como um ator e da (ii) importância da rede de atores para sua implementação nos países participantes, vamos buscar analisar os estudos da Antropologia da Tecnologia, por compreender que este é um caminho que possibilita a elaboração de um arcabouço teórico conectado com essas duas necessidades.

Na Antropologia da Tecnologia, o esforço primordial dos pesquisadores é ressignificar a compreensão de ator social, como, por exemplo, a ideia de dualismo, no debate crítico da natureza humanizada ou de como a bomba Bush do Zimbábue foi elaborada e elabora a comunidade; os autores estão dedicados, nesses escritos, a requalificar a compreensão de ator social (LATOUR, 1993; PFAFFENBERGER, 1988; DE LAET E MOL, 2000). Agora, traz-se para o centro do debate o entendimento da categoria não-humana, neste caso, tratando especificamente da tecnologia, entendendo que é papel da Antropologia da Tecnologia apresentar as relações sociais e políticas que estão na formulação das tecnologias.

A leitura mais densa é a de Bruno Latour, que reposiciona a sociedade, questionando a leitura sociológica tradicional pelo seu dualismo. Para o autor, nesse sentido, a sociedade estaria se transformando em uma "besta muito estranha", pois ela "reflete e se materializa em todos os objetos falsos que meros atores acreditam ser a causa da sociedade", ou seja, a sociedade agora é "forte suficiente para ser sui generis", mas "tão fraca e plástica que a ciência e a tecnologia impõem consenso aos membros sem estabelecer nenhum fato ou artefato" (LATOUR, 1993, p. 374 - 376, tradução própria). O dualismo, ou o enigma que ele coloca aos cientistas sociais, em que ou a sociedade é forte e os objetos são fracos, ou os objetos são muito fortes e a sociedade é fraca, alocará sempre o objeto analisado em um desses extremos e nem a sociedade, nem a tecnologia têm como ocupar algum dos polos (LATOUR, 1993). Aqui o ator, tecnologia ou sociedade, está intrínseco a uma rede na qual influência e é influenciado, sendo impossível se manter apenas em uma dessas condições. 


\section{Revista \\ Debates Insubmissos}

Esta crítica é muito próxima daquela formulada por Bryan Pfaffenberger (1988), anterior à LATOUR (1993), que produz uma nova leitura da tecnologia, como ator social total - no sentido usado por Mauss -, formulando sua crítica sobre dois pilares, o determinismo e o sonambulismo tecnológico. O sonambulismo tecnológico é oriundo da perspectiva ${ }^{4}$ sobre a tecnologia da cultura ocidental que torna a relação humana com a tecnologia óbvia e, moral e eticamente, neutra. Nega totalmente os reflexos, na estrutura e no significado, que o uso de tecnologias reverbera para a vida humana - recebe influência. O determinismo tecnológico apresenta a tecnologia, apenas, como causa das formações sociais, como variável independente - influenciadora. E apresenta as relações sociais e políticas como dependentes e influenciadas pela tecnologia. O que é unitário, nos dois conceitos, é que as relações sociais que possibilitam o surgimento das tecnologias estão invisíveis, seja pela compreensão neutra do sonambulismo ou por sua taxação quanto independente no determinismo tecnológico. Essa invisibilidade, segundo o autor, propicia um entendimento da tecnologia semelhante à ideia marxista sobre o fetichismo da mercadoria, ou seja, a tecnologia é (des)percebida do cotidiano da vida humana sem qualquer envolvimento social; são apenas produtos e ferramentas.

O que Pfaffenberger (1988) procura é estabelecer o entendimento de que a tecnologia deve ser compreendida como "natureza humanizada", em outros termos, é ator social total - ao mesmo tempo político, social e simbólico - produzido por um conjunto de relações sociais e políticas e que, simultaneamente, influência a (re)produção de sistemas de significados da/na sociedade. Reforça a ideia de que a tecnologia, como ator, não está em uma cadeia de causalidade unidirecional, mas em um contexto mais complexo onde influencia e é influenciada simultaneamente. Analisando a bomba de Bush, de Laet e Mol (2000) irão relatar sobre como essa tecnologia é transformada pela comunidade, ao mesmo tempo em que influencia mudanças significativas na dinâmica comunitária.

Até o momento podemos captar, em suma, o entendimento de que um ator social pode ser algo não-humano, ou seja, a variável protagonista no cenário em pesquisa pode assumir o

\footnotetext{
${ }^{4} \mathrm{O}$ autor não assume essa posição claramente, deixando implícito que a perspectiva da cultura ocidental, que produz esse sonambulismo tecnológico, não é apenas sobre a tecnologia, mas também sobre fazer ciência. Ou seja, é a noção de neutralidade científica.
} 
caráter de algo além da ação humana - por mais que também seja resultado disso. Para o entendimento da Open Government Partnership, ator social não-humano e sim tecnológico, em outros termos, os estudos da Antropologia da Tecnologia nos respondem, de forma contundente, à primeira necessidade: reconhecer e estudar a Open Government Partnership como o ator. E o trajeto reflexivo consegue responder, também, a outra necessidade: a importância da rede de atores na sua implementação nos países participantes (ou na não implementação). Nesse ponto, devemos arraigar a argumentação nos debates conceituais e metodológicos de Laet e Mol (2000) no clássico trabalho sobre a performance de adaptação e flexibilidade da bomba d'água elaborada no Zimbábue.

Para Laet e Mol (2000), enquanto compreendem todo o ciclo - elaboração, implementação e monitoramento - da Bomba Bush no Zimbábue, irão defender a ideia de que a compreensão de ator, pensando na tecnologia, não deve assumir a posição sociológica tradicional de racionalismo, mas sim de fluidez.

Porque ao viajar para lugares "imprevisíveis", um objeto que não é rigorosamente limitado, que não se impõe, mas tenta servir, que é adaptável, flexível e responsivo em resumo, um objeto fluído - pode muito bem ser mais forte do que aquele que é firme (LAET E MOL, 2000, p. 226, tradução própria).

Diante disso, vamos refletir algumas variáveis da OGP segundo as definições dos autores acerca da ideia de ator: 1) Não é rigorosamente limitado: a OGP não tem um propósito único, são quatro princípios norteadores, independentes e complexos; 2) Que não se impõe: não há imposição política-institucional, tão pouco legal, a OGP é uma iniciativa dos atores envolvidos desde a sua criação; 3) Tenta servir: a OGP se apresenta como iniciativa que busca ressignificar o Estado para melhor atender às demandas das sociedades; 3) Adaptável: conforme a configuração dos atores envolvidos e da orientação do Estado nacional vai assumir desde políticas de acesso a dados e informações até formação técnico-política de civis; 4) Flexível: se a OGP compreende a importância da participação social para que, na ação crítica, possam reformular o Estado, automaticamente se coloca também sob essas discussões e; 5) Responsivo: há clara relação de responsabilidade entre os participantes, locais e globais, bem como a cobrança, entendendo que essa responsabilidade não é aquela que identificamos na letra da lei, mas sim de compromisso político assumido com os demais. 


\section{Revista \\ Debates Insubmissos}

Se a tecnologia é adaptável, flexível e responsiva, o objeto é fluído - assim como seus limites e avaliação de suas atividades -e inevitavelmente haverá um "herói fluido", ou seja, não há um ator responsável para todo o ciclo dessa tecnologia, devendo ser entendida pela parte estudada. Claro que estão analisando uma tecnologia específica em ambiente específico, o que lhes permite o entendimento elaborado, no entanto, vale a afirmação de que para tecnologias fluidas seja necessário um tipo específico de pessoas: sujeitos não modernos - embutida crítica à cultura ocidental feita por Pfaffenberger (1988) -, dispostos a servir e a observar; com capacidade de ouvir, e que não procurem controlar, mas entender a ousadia de entregar o ciclo às circunstâncias - a ideia latouriana de não assumir entendimento engessado do objeto, mas sim a perspectiva de influenciar e de ser influenciado.

Segundo Laet e Mol (2000), será a aldeia a organização padrão em que se baseia a intervenção, dessa maneira, a bomba não só serve às comunidades para mantê-las juntas, mas também ajuda a distribuir água limpa, ao passo que constrói a nação.

Quando no herói fluído ${ }^{5}$, na elaboração de Laet e Mol (2000), fica nítido que não se trata de um ser iluminado e despendido em busca de atender sua missão cósmica - por mais que em casos extremos possamos observar essa experiência. Tampouco o herói é tratado como sendo alguém em específico. O que os autores abordam é a perspectiva coletiva, a rede de atores distintos que compreendem a importância da implementação e desenvolvimento de determinada tecnologia e que, diante disso, se pré-dispõem a ser variáveis significativas para o seu sucesso.

Posto isso, é inevitável, quase que uma força atraente, debater especificamente a Open Governement Partnership como ator social também nesses termos. Desde o seu princípio é dita sua dependência dos stakeholders, ou seja, seu sucesso, usando os termos de Laet e Mol Laet e Mol (2000), depende do sucesso de se criar uma comunidade com coesão de princípios e

\footnotetext{
${ }^{5}$ O herói fluído, para Laet e Mol (2000), no sucesso da bomba d'água do Zimbábue, foi o Doutor Peter Morgan, vencedor do Prêmio da Água de Estocolmo 2013, pela revolução que proporcionou na saúde de milhões de pessoas por meio de avanços sanitários por esta tecnologia. Dr. Morgan é o fio condutor de toda essa inovação e foi reconhecido pelo próprio engenheiro ErwinVon Elling, tratado durante algum tempo como o responsável, que afirmou: "A bomba é realmente uma invenção do Dr. Morgan. É coisa dele. Nós apenas fabricamos isso"
} 
objetivos, do contrário não passará de mero recurso político-retórico e que nada muda objetivamente a maneira com que o Estado se relaciona com sua sociedade.

Além do mais, porque Laet e Mol (2000) afirmam que, sendo os limites fluidos, os critérios para avaliar o(s) sucesso(s) não são claros.

Os critérios para o sucesso não são claros (fornecer água ou saúde?; construir comunidades ou nação?). Portanto, a bomba Bush do Zimbábue não tem apenas limites fluidos, mas a avaliação de suas atividades também é fluída (LAET E MOL, 2000, p. 248, tradução própria).

Ou seja, mesmo diante do exercício do estabelecimento de uma comunidade coesa nos princípios e objetivos para implementação da OGP, os resultados podem ser diversos, assim como o entendimento de sucesso. A criação dessa comunidade por si só pode vir a ser entendida como sucesso, mesmo não apresentando resultados práticos ou sem sucesso. Assim, quando na avaliação da Open Government Partnership, é preciso reconsiderar sua fluidez e estabelecer parâmetros a partir da "comunidade" formada para implementar essa tecnologia nas suas respectivas nações, diante de seus desafios, históricos ou contemporâneos, singulares. É o passo teórico que a próxima seção dará, abordando especificamente a Teoria Ator-Rede como "lupa" analítica da OGP.

\section{A TEORIA ATOR-REDE PARA A OGP}

Nesta seção vamos abordar outros pontos sobre a elaboração do entendimento do ator social nos estudos de Science, Technology and Society de forma que possamos estabelecer conexão com a Teoria Ator-Rede (ANT), variável final deste laboratório teórico. Vimos que a “implicação é que a preocupação do STS com os métodos transborda em algo que não é obviamente metodológico, porque os métodos não podem ser separados de seu contexto social” (LAW, 2015b, p. 03, tradução própria)

Segundo Michel Callon e John Law (1997) os estudos de Science, Technology and Society evidenciam que a distinção entre a ação individual e a ação coletiva, preponderante nos estudos políticos e sociológicos, é mera configuração para a ação ou sua distribuição (CALLON, LAW, 1997, p. 166,). 


\section{Revista \\ Debates Insubmissos}

Assim, para outras configurações, a STS propõe quatro princípios norteadores: 1) O social é heterogêneo; 2) As entidades são redes de elementos heterogêneos; 3) As redes são variáveis na geometria e, em princípio, imprevisíveis e; 4) Todo arranjo social estável é simultaneamente um ponto (indivíduo) e uma rede (coletivo) (CALLON, LAW, 1997). O que os autores defenderam é que a teoria resultante desse entendimento abandona o dualismo do indivíduo/coletivo pela compreensão de que "não-humanos não são simplesmente recursos ou restrições"; Eles intervêm ativamente para "empurrar a ação em direções inesperadas", ao mesmo tempo que as entidades são efeitos interativos, por exemplo, as redes. A ação é, ao mesmo tempo, "imprevisível e real" - cada uma das entidades reunidas é também uma "rede indefinidamente complexa de relações", significando que a ação não pode ser explicada de forma "reducionista" como consequência de qualquer outra ação anterior em particular (CALLON, LAW, 1997 p. 167-168, tradução própria). Em suma, “a teoria supõe, assim, que a ação é equivalente a relações específicas e materialmente heterogêneas. Ou, como poderíamos chamá-los, coletivos híbridos” (CALLON, LAW, 1997 p. 179, tradução própria).

Bruno Latour (1993) reposiciona a sociedade questionando a leitura sociológica tradicional em uma contradição flagrante, que é seu dualismo, como discutimos nas seções anteriores $\mathrm{O}$ dualismo, ou o enigma que ele põe aos cientistas sociais, em que ou a sociedade é forte e os objetos são fracos, ou os objetos são muito fortes e a sociedade é fraca, alocará sempre o objeto analisado em um desses extremos e, nem a sociedade e nem a tecnologia, tem como ocupar algum dos polos (LATOUR, 1993). Aqui o ator, tecnologia ou sociedade, está intrínseco a uma rede na qual influencia e é influenciado, sendo impossível se manter apenas em uma dessas condições.

Pensando de forma crítica na contribuição que a antropologia cultural poderia dar aos estudos da ciência, Emily Martin (1998) produzirá três imagens enigmáticas que caracterizam o ambiente científico e sua relação com o mundo, e vice-versa. A primeira é a ideia de que a ciência, principalmente as ciências naturais, são como uma cidadela, que na compreensão militar se refere a lugar estratégico que domina e protege uma cidade, sendo a cidade, a sociedade. Os métodos são a forma de diálogo entre os integrantes da cidadela e os que vivem 


\section{Revista \\ Debates Insubmissos}

da cidade. Na crítica à visão de acumulação de recursos por parte dos cientistas (presente na visão latouriana e na Teoria Ator-Rede), Martin pontuará que a contribuição da Antropologia é por uma noção abrangente do que é pertinente aos objetos do conhecimento e à prática científica, pois os não-cientistas, oriundos de contextos culturais distintos, mantêm conexões com a cidadela, ao passo que grupos sociais poderosos vão exercer pressões para que o ambiente científico responda aos seus interesses.

Assim, para Martin (1998), a relação da cidadela com a cidade não é unidirecional, na qual o conhecimento científico flui para toda a sociedade. A autora analisa que a relação entre ciência e cultura será descontínua, fraturada e não-linear, elaborando sua segunda imagem, a do rizoma.

A terceira imagem, o jogo de corda ou, como é no Brasil, cama-de-gato, absorve a ideia de que a atividade científica se mistura com o resto da cultura, de forma a montar um emaranhado de características, experiências sobrepostas e entrecruzadas, no contato com uma multiplicidade de atividades fora da ciência e produzindo e reproduzindo dentro da matriz heterogênea da cultura.

A ideia afirmada acima se contrapõe ao método descrito por Law (2015a), a Semiótica Material ou a Teoria Ator-Rede (ANT). O autor entende que a ANT compõe o conjunto ferramenteiro da Semiótica Material e que, apesar da semelhança imagética formulada por Martin, está fora do campo da etnografia. A Semiótica Material retoma a ideia de diferença de Law (2015b) compreendendo a multiplicidade de ordens sociais, negando a ideia de que existe uma única ordem social e que não há um grande princípio que organiza tudo e todos e sim a construção de narrativas. A realidade posta é de um eterno e grande encontro cultural, sendo impossível tratarmos os fenômenos estudados pela STS sem reconhecer e respeitar as diferenças que já convivem. Dessa forma, é imposto ao cientista que compreenda que, ao escolher um objeto ou uma cena, está optando por analisar pequena parte de todo esse tecido, o que vai requerer um conjunto de sensibilidades e ferramentas capazes de auxiliar na compreensão deste universo múltiplo e complexo. 


\section{Revista \\ Debates Insubmissos}

Para Law (1992; 2008, p. 01-02, tradução própria) a Teoria Ator-Rede, sendo uma forma de escrita analítica baseada no empirismo que trata as relações sociais - poder e organizações, por exemplo - como efeitos de rede, é melhor entendida se pensarmos como um "kit de ferramentas para contar histórias interessantes e interferir nessas relações". A ANT ajuda na compreensão da mecânica do poder e das organizações, mas o pesquisador deve partir da postura de não assumir o que deseja explicar. O método é descritivo, pois o resultado final pode ser meramente a interação estudada (LAW, 1992). Em síntese, a Teoria Ator-Rede, criada em Paris entre 1978 e 1982 por Michel Callon, pode ser compreendida em diálogo com as formulações dos discursos de Michel Foucault (1979), assim como versões empíricas da filosofia de Gilles Deleuze (1995). Dessa forma, a ANT e caracteriza-se: a) É possível descrever a teoria em abstrato (estudos de casos empíricos); b) A abordagem da rede de atores não é uma teoria. A teoria da rede de atores é descritiva e não tenta explicar por que algo acontece (conjunto de sensibilidades para a prática); c) Todo o mundo é relacional; d) É uma diáspora que se sobrepõe a outras tradições intelectuais (LAW, 1992; 2008).

Podemos, enfim, destacar algumas características refletidas nessa subseção para pensarmos a Open Government Partnership como objeto a ser estudado pela Teoria Ator-Rede: a) A abordagem que abandona o dualismo de indivíduo/coletivo e que o ator, a OGP, é parte de uma rede na qual influencia e é influenciado (CALLON, LAW, 1997; LATOUR, 1993); b)A compreensão da relação contínua entre ciência e cultura (MARTIN, 1998) e; c) A multiplicidade de ordens sociais e a construção de narrativas, sendo a realidade um grande encontro cultural (LAW, 1992; 2008; 2015a; 2015b).

\section{CONCLUSÕES}

Conclui-se que a Open Government Partnership (OGP) pode ser compreendida como ator dentro do campo científico da Science, Technolgy and Society (STS), caso a leitura analítica seja na área da Antropologia da Tecnologia. 
Dentre os conceitos que merecerem destaques estão a ideia do fim do dualismo entre indivíduo/coletivo, a possibilidade de atores não-humanos, limites e avaliação fluida incluindo a possível compreensão de um "herói fluido" -, a importante compreensão da não distorção de seus princípios na implementação em nações distintas e a ideia de tecnologia adaptável, flexível e responsiva. Mas, também, que o ator é parte de uma rede complexa que influencia e pela qual é influenciado, que a ciência e a cultura lhe são intrínsecas, sendo a realidade uma disputa entre inúmeras narrativas e ordens sociais.

Na resposta objetiva das reflexões iniciais - (i) reconhecer e estudar a OGP como o ator e a (ii) importância da rede de atores para sua implementação nos países participantes - se aloca a contribuição significativa e original desse artigo. É necessário optarmos por uma análise de ator-rede para compreender a Open Government Partnership, pois nos auxilia a entender que a própria OGP é ator principal que incide sobre a(s) rede(s) de outros atores, ao passo que esses também têm certa liberdade para se adequar segundo as necessidades, peculiaridades, objetivos e conjunturas (narrativas) que estão submetidos.

\section{REFERÊNCIAS}

BRASIL. Decreto $\mathrm{n}^{0} \mathbf{1 0 . 1 6 0}$ de 09 de dezembro de 2019. Institui a Política Nacional de Governo Aberto e o Comitê Interministerial de Governo Aberto. Acesso 10 de outubro de 2020. Disponível em: https://pesquisa.in.gov.br/imprensa/jsp/visualiza/index.jsp?data=10/12/2019\& jornal $=515 \&$ pagina $=3 \&$ totalArquivos $=181$

BRASIL. Memória de Reunião Grupo de Trabalho para Assessoramento em Governo Aberto. 03 e 04 de dezembro de 2015.

BRASIL. Monitoramento e execução da iniciativa - Controladoria-Geral da União. Acesso em 09 de outubro de 2020. Disponível em: https://www.gov.br/cgu/pt-br/governoaberto/a-ogp

BRASIL. Manual Parceria para Governo Aberto, 2014. Acesso em 28 de março de 2018. Disponível em: http://www.governoaberto.cgu.gov.br/central-de-conteudo /documentos/arquivos/manual- dialogo-presencial-ogp.pdf/. 
CALDERÓN, César; LORENZO, Sebastián. Open Government: Gobierno Abierto. Editora: Algón Editores, Colección Algón Nº 5, abril, 2010.

CALLON, M.; LAW, J. After the Individual in Society: Lessons on Collectivity from Science, Technology and Society. The Canadian Journal of Sociology / Cahiers canadiens de sociologie, Vol. 22, No. 2, pp. 165-182, 1997.

DE LAET, Marianne; MOL, Annemarie. The Zimbabwe Bush Pump: Mechanics of a Fluid Technology. Social Studies of Science, 30 (2) : 225-263, 2000.

DELEUZE, Gilles e GUATTARI, Félix. Mil Platôs. Capitalismo e Esquizofrenia. Rio de Janeiro: Editora 34. 715 pp, 1995.

FOUCAULT, Michel. Discipline and Punish: The Birth of the Prison. Harmondswort. Trad.: Alan Sheridan, 1979. Acesso em 20 de março de 2018 Disponível em: https://monoskop.org/images/4/43/Foucault_Michel_Discipline_and_Punish_The_Birth_of_t he_Prison_1977_1995.pdf.

LATOUR, Bruno. Ethnography of a 'high-tech' case: about Aramis. In: Pierre Lemonnier (org.) Technological Choices: Transformation in Material Cultures Since the Neolithic. London: Routledge, pp. 372-398, 1993.

LAW, John. Actor network theory and material semiotics. The new Blackwell companion to social theory. West Sussex: Wiley, pp. 141-158, 2008.

LAW, John. Material Semiotics. Acesso em 28 de março de 2018. Disponível em: http://heterogeneities.net/papers.htm. 2015a.

LAW, John. Notes on the theory of the actor-network: Ordering, strategy, and heterogeneity. Systems practice, v. 5, n. 4, p. 379-393, 1992.

LAW, John. STS as method. Acesso em 28 de março de 2018. Disponível em http://heterogeneities.net/papers.htm. 2015b

MARTIN, Emily. Anthropology and the cultural study of science. Science, Technology \& Human Values, 23(1):24-44, 1998.

MÉXICO. Minuta - Reunión de Trabajo - Alianza para el Gobierno Abierto (AGA). 27 de febrero de 2019.

OGP, Open Government Partnership. Declaração de governo aberto. Setembro, 2011. 
OGP, Open Government Partnership/Brasil. Memória de Reunião Grupo de Trabalho para Assessoramento em Governo Aberto, 2015. Acesso em 04 de fevereiro de 2018. Disponível em: http://www.governoaberto.cgu.gov.br/noticias/2015/i-reuniao-do-gt-sociedade-civil.

PFAFFENBERGER, Bryan. Fetishised Objects and Humanised Nature: Towards an Anthropology of Technology. Man, New Series, 23(2):236-252, 1988.

SANTOS, Boaventura de Sousa (Org.). Democratizar a Democracia: os caminhos da Democracia Participativa - Reinventar a emancipação social: para novos manifestos. Rio de Janeiro: Civilização Brasileira, 2002.

SANTOS, Matheus H. de S.; SERAFIM, Milena P. Open Government Partnership (OGP) como inovação no setor público: Análise acerca da Matriz Inovativa e da Tecnologia Emergente. Anais XXIII Congreso Internacional del Centro Latinoamericano de Administración para el Desarrollo (CLAD) sobre la Reforma del Estado y de la Administración Pública, 2018. Disponível em: https://www.clad.org/congresos/xxiv-congreso.

TRAWEEK, Sharon. An introduction to cultural and social studies of sciences and technologies. Culture, Medicine and Psychiatry 17:3-25, 1993.

Submetido em: 27/11/2020

Aprovado em: 15/12/2020 